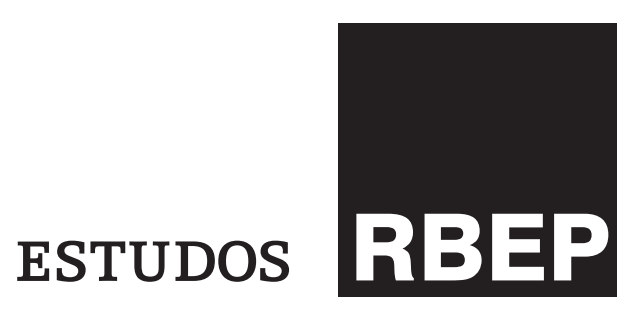

\title{
O brincar e o cuidado nos espaços da educação infantil: desenvolvendo os animais que somos
}

\author{
Rodrigo Avila Colla ${ }^{\mathrm{I}, \text { II }}$
}

http://dx.doi.org/10.24109/2176-6681.rbep.100i254.3956

\footnotetext{
Pontifícia Universidade Católica do Rio Grande do Sul (PUC-RS). Porto Alegre, Rio Grande do Sul, Brasil. E-mail: $<$ rodrigo.a.colla@gmail com>; < https://orcid.org/00 00-0002-2638-8117>

II Doutor em Educação pela Pontifícia Universidade Católica do Rio Grande do Sul (PUC-RS). Porto Alegre, Rio Grande do Sul, Brasil.
}

\begin{abstract}
Resumo
O presente artigo discute o brincar e o cuidado como tarefas constitutivas do desenvolvimento humano. Para tanto, vale-se de contribuições teóricas de autores que são referências na área de educação infantil. A organização do espaço, nessa etapa, e a disponibilização de materiais adequados também são tematizadas e tratadas como práticas relevantes na formação. O texto problematiza a animalidade humana como um conjunto de potências a serem observadas nas crianças. Na proposta aqui defendida, a pedagogia da primeira infância deve estar atenta a tais potências, bem como deve fomentar a livre iniciativa das crianças, propiciando condições para que realizem suas descobertas de modo lúdico. Nesse processo, o cuidado também é algo indispensável e consiste na disposição dos animais que somos, que é inextricável do ato de educar.

Palavras-chave: animalidade; brincar; cuidado, educação infantil, espaço escolar.
\end{abstract}




\section{Abstract \\ Playing and care-taking in child education environments: developing the animals that we are}

This article discusses playing and care-taking as tasks that are part of human development. To do so, it counts on theories of authors who are a reference in early childhood education. Environmental organization, at this stage, and the offering of appropriate materials are also deemed as relevant practices and a theme in the formative process. The text problematizes human animality as a set of forces to be observed in children. In this proposition, early childhood pedagogy must be attentive to it and it must promote children's free initiative, giving them the conditions to playfully make their discoveries. Within this process, care-taking is also indispensable and consists on the displaying of the animals that we are, which is inextricable from the act of educating.

Keywords: animality; playing; care-taking; early childhood education; school environment.

\section{Resumen \\ El jugar y el cuidado en los espacios de educación infantil: desarrollando los animales que somos}

Este artículo discute el jugar y el cuidado como actividades constitutivas del desarrollo humano. Para tanto, se vale de contribuciones de autores que son referencias en el área de educación infantil. La organización del espacio, en esta etapa, y la disponibilidad de materiales adecuados también son tematizadas y tratadas como prácticas relevantes en la formación. El texto problematiza la animalidad humana como un conjunto de potencias a ser observadas en los niños. En la propuesta aquí defendida, la pedagogía de la primera infancia debe estar atenta a dichos potencias, así como debe, también, fomentar la libre iniciativa de los niños, propiciando condiciones para que realicen sus descubiertas lúdicas. En este proceso, el cuidado también es algo indispensable y consiste en la disposición de los animales que somos, que es inextricable del acto de educar.

Palabras clave: cuidado; animalidad; jugar; espacio escolar; educación infantil; .

\section{Apresentação}

Um primeiro ponto a ser esclarecido é que a brincadeira, aqui, é considerada como uma atividade pedagógica. Não compactuo com a visão 
tradicionalmente propagada pelo senso comum de que a brincadeira (e, por conseguinte, a hora de brincar) é um momento considerado incompatível com as preocupações relacionadas ao ensino e à aprendizagem. A despeito da importância que se atribui à educação, o processo de ensinoaprendizagem não deve pressupor a ausência de ludicidade, principalmente no que diz respeito ao tratamento com crianças pequenas. Para elas, a brincadeira é uma experiência de autoprodução, isto é, elas se criam e se recriam ao brincar. Nesse viés, atividades (e aprendizagens) significativas para a criança são aquelas que despertam seu interesse, geram prazer e convidam a penetrar no universo lúdico.

Em segundo lugar, animalidade aqui entendida, obviamente, não diz respeito ao retorno a um estado natural ou à experienciação de condições primitivas ou ações orientadas puramente pelos instintos, mas a um conjunto de potências próprias dos animais que somos e passíveis de estarmos a serviço da educação. O corpo por meio do qual experienciamos essas potências é o mesmo que se entrega à brincadeira e se transforma por meio dela. $\mathrm{O}$ ato de brincar é entendido como uma possibilidade de experienciar essas potências. O corpo é o ser mesmo, o templo primordial dos animais que somos, mutantes, animados por nossas animalidades e, em idade tenra, entregues à plenitude do verbo viver - desejar mais e mais vida, que é a potência do próprio desejo (Nietzsche, 2003). Nessa espécie peculiar que somos não há vida sem cuidado. Nascemos completamente dependentes dos indivíduos adultos que compõem nossa família. Ao longo do tempo, somos cuidados e educados até que adquirimos a aptidão de cuidar de nós mesmos. A legislação brasileira destaca que as instituições de educação infantil devem assumir "a responsabilidade de compartilhar e complementar a educação e cuidado das crianças com as famílias" (Brasil. CNE. CEB, 2009, p. 2). Enquanto o verbo educar está historicamente atrelado mais fortemente à pedagogia e, de maneira geral, é entendido como a ação que visa a formar sujeitos para a sociedade, considerando determinados valores e práticas - ou, como sustenta Libâneo (2001, p. 97), o ato de "conduzir de um estado a outro" -; cuidar conota a "ideia de preservação da vida, de atenção, de acolhimento, envolvendo uma relação afetiva e de proteção" (Faria; Salles, 2007, p. 52).

Este texto tem o objetivo de pensar a tarefa de cuidar, própria do(a) educador(a) de crianças pequenas, e a brincadeira, respectivamente, como necessidade e como meio de expressão/potenciação do animal humano. Ambas são pensadas e articuladas com um fator considerado de extrema relevância: a organização do espaço na educação infantil.

\section{Animais brincantes}

Fortuna (2014) esclarece que, nas línguas românicas e germânicas, a palavra jogo conota a ideia de movimento. O brincar, por sua vez, é uma "apropriação ativa do real por meio da representação" (Fortuna, 2014, p. 24). Isso quer dizer que a brincadeira também possui certos códigos, lógicas internas que preparam o sujeito que brinca para a socialidade e que 
contribui para o exercício desta. É próprio do animal humano, aliás, esse pendor para a socialização. Trata-se de um animal de bando. Quando me refiro ao jogo, o incluo no rol de atividades lúdicas brincantes. O jogo não deixa de ser uma brincadeira. Se ele possui regras mais explícitas e acordo prévio entre os participantes, isso não deixa de ser um detalhe diante do fato de que, em qualquer caso, ele é uma atividade recreativa, lúdica e com um fim em si mesma, tanto quanto a brincadeira. Não obstante, se os jogos muitas vezes também são praticados por adultos, as brincadeiras são quase que exclusivamente atividades infantis, e sua experiência "nos possibilita rica aproximação e envolvimento com as crianças, encontrando-as em seu tempo singular de descobertas, de invenção, de conhecimentos, de vivências de infinitas formas humanas de expressão e de linguagem" (Debortoli et al., 2009, p. 107). No universo da infância, a brincadeira é uma linguagem e não meramente um momento de recreação. O impulso para brincar transcende um desejo de se divertir; é, antes, uma prática que visa a suprir a necessidade de conhecer e de se comunicar.

Santos (2012) elenca três tipos de estruturas que caracterizam as atividades lúdicas: exercício, símbolo e regra. Exercício consiste em uma prática realizada pelo prazer que ela propicia (picar uma bola, lançar um objeto etc.), enquanto o jogo simbólico "pressupõe a representação de um objeto ausente" (Santos, 2012, p. 124). Do exercício, em que comumente ocorre a repetição e a sobreposição, a criança adentra em um novo universo que amplia sua percepção e sua sensibilidade. A imaginação e a abstração ganham importância central. Se compartilhamos a capacidade de ação com uma miríade de espécies animais, a representação é própria do animal humano. Outros animais não são capazes de "fazer de conta", representar ou abstrair, e são justamente essas capacidades que nos tornam também aptos para o desenvolvimento da linguagem. Por fim, Santos (2012) destaca que o jogo de regras é caracterizado principalmente pela interação social. Ele só pode ser jogado mediante um acordo mútuo entre os participantes em relação a suas regras. É a esse tipo de atividade lúdica que comumente nos referimos simplesmente com a palavra jogo. Ela costuma ser praticada pelas crianças mais tardiamente, a partir dos 7 anos de idade, e possui também grande adesão do público adulto.

A brincadeira, tanto quanto o jogo, é uma entrega. No sentido coloquial, jogar-se, aliás, é entregar-se, é lançar-se de corpo e alma. Entregar-se é fruir aquilo a que estamos entregues e deixar que a torrente de acontecimentos que se originam nessa relação nos conduza. Diz-se isso dos amantes, inclusive. Entregam-se quando a plenitude de seus seres ocorre no amor, e é o próprio amor que move suas decisões, suas atitudes. Entregam-se quando são amantes. Jogar é ser jogador. Brincar é ser brincante. É deixar que o jogo ou a brincadeira ajam sobre o participante e o transformem, pois, como afirma Paulo Fochi (2015), respaldando-se em Jerome Bruner, as crianças fazem uma constante avaliação e adequação nas atividades que realizam. Mesmo quando a metamorfose parece imperceptível, esse círculo de avaliações e adequações está ocorrendo e as transformando.

Nas palavras de Pereira (2009, p. 20), o jogo é uma atividade "livre, delimitada (no espaço e tempo), incerta, improdutiva, regulamentada e 
fictícia". Da brincadeira se pode dizer praticamente o mesmo. Segundo o autor, "todo brincar tem início a partir de uma vontade" (Pereira, 2009, p. 21). O ato de brincar, nesse sentido, é ao mesmo tempo uma forma de expressão e não uma ferramenta. A finalidade da brincadeira é a própria brincadeira. Ela não é um meio para se chegar a determinado fim. Brincar é experienciar um viés formativo próprio do humano.

Na mesma senda, Faria e Salles (2007) apostam em uma proposta pedagógica lúdica em que o brincar é visto como uma forma privilegiada de fomentar a aquisição da função simbólica. Esta, no argumento das autoras, "possibilita às crianças compreender o mundo e se expressar também através da linguagem plástica e visual" (Faria; Salles, 2007, p. 76). A brincadeira é tratada por elas como uma linguagem, assim como a escrita, a oralidade, as artes visuais, a música e a corporeidade. A brincadeira, entendida como linguagem, se configura por meio da "capacidade humana de imaginar, de transformar uma coisa em outra, de dar significados diferentes a determinado objeto ou ação" (Faria; Salles, 2007, p. 76). Nota-se, nesse ponto, que as autoras parecem priorizar o potencial humano para transcender a prática dos jogos de exercício. Isso não é de todo estranho se levarmos em conta que se trata justamente de pensar a brincadeira como linguagem, como meio de expressão e como prática por intermédio da qual "a criança suporta, no mundo do faz de conta, uma situação real, habilitando-se a compreendê-la. Por meio do simbolismo do brinquedo, transfere interesses, fantasias, ansiedades e sentimentos de culpa" (Fortuna, 2014, p. 23). Pensar o potencial educativo da brincadeira tende a nos levar a essa priorização dos aspectos culturais ou humanos que tais práticas encerram, mas, como bem frisam Faria e Salles (2007, p. 70), a capacidade de brincar "se constrói na relação entre o biológico e o cultural". O aspecto biológico, pode-se dizer, se refere tanto a nossa constituição física quanto a emoções e sentimentos. Não significa, no entanto, que todos os aspectos culturais ou estritamente humanos da nossa existência não tenham raízes em nossa animalidade, mas é compreensível nossa obsessão em promover a cisão entre natureza e cultura, e não é um disparate a considerarmos como uma característica própria dos animais que somos, como uma entre tantas investidas no sentido de nos diferenciarmos e, produzindo diferenciações, nos tornarmos animais culturais, sociais, políticos etc.

Mesmo tomando como ponto de partida essa cisão, que não deixa de ser um antropomorfismo, é possível pensarmos na brincadeira como uma atividade que dá vazão às potências de nossa animalidade. Do ponto de vista biológico ou etológico, somos animais, não por acaso, capazes de sorrir e de expressar sentimentos de modos bastante variados. Assim, o pendor para a brincadeira e o contentamento propiciado por ela - considerando a brincadeira como modo de expressão privilegiado de nossas crias em idade precoce - podem ser encarados como potências da animalidade humana. Potências, aliás, que compartilhamos com outras espécies de mamíferos. A brincadeira, segundo essa interpretação, ao mesmo tempo supre necessidades de exploração e ajuda a desenvolver potencialidades dos animais que somos. 
Em livro dedicado ao tema do atendimento às crianças em creches, Goldschmied e Jackson (2006) consideram a certificação, por parte do educador, de que a criança esteja feliz um aspecto essencial do trabalho pedagógico. A exemplo de Fortuna (2014), as autoras salientam, ainda, a importância da organização do espaço das salas de aula para potencializar a experiência das crianças tanto com os objetos disponíveis como com os(as) colegas e os(as) docentes.

A exploração dos espaços e objetos, para a criança, é uma atividade lúdica que propicia a alegria da descoberta de si e do outro e contribui para o seu desenvolvimento. A organização do espaço e a intervenção do adulto podem facilitar ou dificultar essa exploração. Fochi (2015) afirma que se faz urgente investigar as ações das crianças e embasar essas ações no universo teórico da pedagogia. Considera particularmente importantes "aquelas em que a intervenção direta do adulto é mínima" (Fochi, 2015, p. 58). Na visão do autor, na maioria das ocasiões, o adulto deve intervir apenas para garantir o bem-estar das crianças, sabendo "observar os processos de exploração das crianças pequenas a partir delas mesmas" (Fochi, 2015, p. 151). Fortuna (2014), por sua vez, defende que dar liberdade às crianças não significa a completa omissão do docente. Destarte, o(a) educador(a) infantil também deve saber intervir nas brincadeiras de seus educandos de modo provocativo e desafiador.

Goldschmied e Jackson (2006) trabalham com uma perspectiva que merece ênfase aqui. O "brincar heurístico com objetos", segundo as autoras, "envolve oferecer a um grupo de crianças, por um determinado período e em um ambiente controlado, uma grande quantidade de tipos diferentes de objetos e receptáculos, com os quais elas brincam livremente e sem a intervenção de adultos" (Goldschmied; Jackson, 2006, p. 147). A meu ver, essa categoria trazida à tona pelas pesquisadoras contempla aspectos centrais para este artigo: o cuidado, a brincadeira como exploração e via de potenciação da animalidade, e a importância do espaço nesse processo.

\section{O espaço como instância constitutiva e de cuidado}

Partindo de matriz teórica que mescla a ontologia heideggeriana com a antropologia filosófica das relações de Serres, Nörnberg (2013), em artigo intitulado Do Berço ao Berçário: a instituição como morada e lugar de contato, propõe uma releitura dos espaços e instituições destinados às crianças como espaço de cocriação em que as crianças, obviamente, devem ser consideradas copartícipes e ter suas aptidões para a democracia exercitadas. Ela quer, de fato, "pensar a dimensão coletiva que é própria do viver humano em instituições" (Nörnberg, 2013, p. 102). As ações dos bebês no âmbito coletivo são também objeto de estudo de Fochi (2015), e a escola é entendida como um conjunto de contextos de vida coletiva. Em sua pesquisa, ele considera ser mais importante planejar "o tempo, os espaços, os materiais, a organização do grupo e o tipo de intervenção" (Fochi, 2015, 
p. 151) do que atividades específicas. Ao adulto, cabe propiciar as condições necessárias para que os bebês vivam a experiência de ser bebê, bem como assegurar o seu bem-estar. Uma postura pedagógica dessa natureza contribui para construção da autonomia e para o desenvolvimento da ação de comunicar dos bebês, pois ela está apoiada "na premissa relacional e social do ser humano; e [...] na ação do bebê sobre o outro, em outras palavras, a linguagem do bebê se vale de sua ação para se efetivar" (Fochi, 2015, p. 102). Nesse mesmo viés, Faria e Salles (2007) incluem o brincar no rol das linguagens da criança. Ora, para Heidegger (1967), a linguagem é a morada do ser. O humano é o animal que se pergunta pelo que é, e a pergunta advém de sua condição de ser o animal da linguagem. A ação, no caso dos bebês, é, portanto, uma manifestação comunicativa dos animais que somos.

Concordo com Nörnberg (2013, p. 102) quando ela explica o ser-nomundo (ser-aí) - pressuposto heideggeriano que designa a condição do ser que se pergunta pelo que é - como o "ser-no-mundo-junto-das-coisas-comoutros". A autora defende, assim, que "os espaços do berço ao berçário são (auto)constitutivos do ser bebê" (Nörnberg, 2013, p. 103). Ao se movimentar nesses espaços e habitá-los, a criança adquire certo protagonismo em sua própria formação. O trabalho de Fochi (2015) faz ecoar esse argumento, mas Barbosa e Horn (2008) levantam outros aspectos relevantes e são ainda mais taxativas no que concerne à importância da organização espacial nas instituições de educação infantil. Na opinião das autoras,

o espaço tem um caráter simbólico, pois oferece um ambiente de cumplicidade, que permite a emergência das singularidades, das diferentes identidades, das experiências, dos sentimentos e das emoções (Barbosa; Horn, 2008, p. 51).

A organização do espaço, afirmam Barbosa e Horn (2008, p. 51), "reflete nossas crenças acerca das concepções de mundo, de criança, de aprendizagem e de educação".

Para que seja possível aproveitar esses espaços, ou melhor, torná-los próprios para o exercício da autonomia e da democracia, fomentando esse poderio (auto)constituidor, é preciso uma pedagogia que reconheça

o cotidiano como lugar espacial e temporal, onde diferentes modos de afetar são colocados em relação de proximidade e coexistência, porque ali são tecidas as ações, as crenças e as teorias. Uma pedagogia que se organiza pelas formas humanas que o corpo produz: o contato, o toque, o olhar, a escuta, o embalar, o mostrar, o segurar, o alimentar. No cotidiano da instituição infantil, do berço ao berçário, estão a força e a vitalidade das relações entre bebês e destes com os adultos, lugar de (re)criação pedagógica. (Nörnberg, 2013, p.103).

Em momento subsequente, Nörnberg explana um cenário educacional típico da sociedade capitalista, em que as instituições passam a valorizar a qualidade em educação, e a informação é o principal indicador passível de avalizar e de ratificar essa qualidade. Esse cenário acaba trazendo uma tendência de avaliar as instituições. Nesse contexto, a autora destaca a pesquisa de Campos et al. (2011) sobre a qualidade da educação infantil no 
Brasil, pesquisa que "mostra que aspectos importantes de uma programação voltada para as crianças pequenas estão sendo negligenciados, na maioria das instituições avaliadas" (Nörnberg, 2013, p. 104).

Campos et al. (2011) avaliam sete categorias das instituições de educação infantil em estados da cinco regiões brasileiras. Entre elas, aqui me interessam particularmente três, a saber: espaço e mobiliário, atividades, e rotinas de cuidado pessoal. Dos aspectos analisados pela pesquisa são esses que considero mais relevantes no que concerne ao tema deste artigo, mas esses aspectos são justamente os avaliados mais negativamente com base nos critérios utilizados (considerando escalas ${ }^{1}$ e questionários).

Na visão de Nörnberg (2013, p. 105),

a escola, ao intensificar um determinado aspecto técnico, instrucional ou de outra natureza, verá frustrada sua tarefa de ser uma das manifestações da existência, que a define como instituição, ou seja, a de promover o encontro inter-humano.

É por isso que a autora argumenta em favor da instituição como domus, como morada comum, como espaço de convivência formativa que forma para a completude do sujeito. Focando sua reflexão no berçário, ela alega que este, enquanto domus,

[...] é lugar de morada e de habitação do bebê que se lança no movimento de relacionar-se e conhecer(-se); por isso, o berçário, como morada, também carrega a responsabilidade de ser lugar de acolher e de permitir a abertura das diferentes formas de estar no mundo, mediante o resguardo dado pelas formas relacionais ali produzidas. (Nörnberg, 2013, p. 106)

O entendimento da instituição como domus dá margem para que se pense na potencialização do "ser-aí" no sentido heideggeriano, pois o ser se autoconstitui, mas também é constituído a partir das potências e das disposições de seu entorno/tempo. O "ser-aí" (Dasein) tem o estatuto ontológico de ser no tempo, no espaço, com os outros e com as coisas. "As diferentes formas de estar no mundo" só podem vir à tona por meio do cuidado, do acolhimento que permite "ser-no-mundo", no "aí" - espaçotempo em que tudo reside e manifesta potência. A cura (sorge), segundo Heidegger (1967, p. 34), "exprime a estrutura ontológica que unifica todos os momentos constitutivos do 'ser-no-mundo'". O cuidado (cura) com as coisas e com os outros, portanto, produz os seres que somos e funda os significados que atribuímos a tudo por meio da linguagem; funda o mundo, ou seja, o espaço-tempo significado no qual somos junto a todo resto (por meio do qual atribuímos sentidos à nossa existência). A disposição do ser-no-mundo (que existe na condição de ser junto a outros seres e a tudo àquilo que está à mão, isto é, que é passível de ser manipulado) não deixa de ter para com ele certo cuidado, constituindo-o. Inarredavelmente, disposto a cuidar, o ser cuida de si. Cuidar e ser cuidado são práticas determinantes para o ser que se pergunta pelo que é ser humano. A cura, assim, é a curadoria do próprio ser que se pergunta pelo que é porque estabelece uma relação de cuidado consigo ao exercitar o cuidado com os outros, com as coisas e com o entorno/tempo. Somos um "ser-no-mundo-junto-das-coisas-com-outros",

\footnotetext{
As pesquisadoras e o pesquisador utilizam as escalas Infant/Toddler Environment Rating Scale-Revised Edition - Iters-R e Early Childhood Environment Rating ScaleRevised Edition - Ecers-R. Explicam que elas são "conhecidas e utilizadas internacionalmente como instrumentos de avaliação da qualidade de instituições de educação infantil. As escalas foram desenvolvidas para ser utilizadas na observação e avaliação de ambientes e/ ou programas voltados ao atendimento de crianças com idade entre 0 e 2 anos e meio (Iters-R) e entre 2 anos e 7 meses e 5 anos (Ecers-R) e com a presença do professor responsável" (Campos et al., 2011, p. 30).
} 
como prefere Nörnberg (2013), que ao exercer uma relação de cuidado com a "outridade" também cuida de si e é cuidado, constituindo-se. Prossegue a autora:

Nesse sentido, o desafio dado pela Antropologia filosófica de Serres lança a tarefa de auscultar os bebês, de ampliar as formas de relação com eles, constituindo uma escuta sensível ao que o corpo do bebê fala, comunica; que estará, quiçá, para além de uma experiência meramente cognitiva, porque reivindica uma participação de corpo inteiro, especialmente mediante o cuidado humano. (Nörnberg, 2013, p. 107)

Inspirada nesse argumento, ela, logo adiante, preconiza: "a prática pedagógica precisa carregar a força de ser um processo construtivo conjunto, que estimula a solidariedade e a participação, garantindo, assim, o exercício democrático" (Nörnberg, 2013, p. 108). Tal pedagogia deve reconhecer o corpo do bebê como "potência de criação e construção de conhecimento" (Nörnberg, 2013, p. 110). Esse reconhecimento deve apostar nas linguagens não verbais, deve passar pelo campo da sensibilidade e fomentar o exercício dessa sensibilidade com os diversos interlocutores desses espaços institucionais, que devem prezar pelo acolhimento e pela qualidade das interações, pois "a relação entre os bebês e os adultos, feita por seus corpos, no contexto do berçário, dá razão de ser à Pedagogia" (Nörnberg, 2013, p. 112).

Percebo um eco do conceito de tato de Helmholtz (apud Gadamer, 1999, p. 57): ${ }^{2}$ "determinada sensibilidade e capacidade sensível para situações e para postar-se nelas, para as quais não possuímos nenhum saber baseado em princípios universais". Embora a autora não tenha se valido da noção cunhada por Helmholtz, não por acaso Gadamer é um dos mais célebres discípulos de Heidegger, a utiliza para explicar o conceito de formação (bildung) na tradição filosófica alemã.

Cabe ressaltar, ainda, que a própria Nörnberg faz ecoar a inextricável relação entre ética e estética na formação (presente tanto no conceito de Helmholtz quanto na teoria de Gadamer), ao dizer que

Pensar uma pedagogia do contato significa compreender que a expressão do berço ao berçário se refere ao próprio movimento que toma corpo institucional para suprir necessidades coletivas, algo que materializa a dimensão ético-estético-afetiva do existir humano. (Nörnberg, 2013, p. 111-112, grifos da autora).

Ao agregar a dimensão afetiva a essa espécie de "dupla inseparável" supramencionada, a autora parece querer trazer à tona novamente a noção de cura interligada às práticas, condutas e modos de ser que se evidenciam no processo formativo. O afeto afigura-se, assim, principalmente no caso do cuidado com bebês, a uma disposição "curadora" por excelência. O grifo no radical da palavra contato permite que tragamos à baila o conceito de Helmholtz no contexto da prática docente com crianças pequenas. Nörnberg (2013), como mencionei, não desenvolve esse conceito em seu artigo e sua principal preocupação é discutir a instituição berçário como espaço social 
de formação e cuidado, mas, ao desenvolver seu argumento, a autora não se furta da tarefa de tecer considerações sobre atitudes pedagógicas que contribuam para fabricar esse espaço por ela idealizado. Nesse sentido, jamais poderão ser os "princípios universais" que regerão a prática docente, mas o tato para saber observar as crianças, suas ações, para se dispor a experienciar o inédito com elas, ser cúmplice de suas descobertas, oferecendo condições para que supram seus desejos de descobrir sem, contudo, incitá-las em demasia e, atabalhoadamente, desrespeitando seus tempos.

Ao discutir a importância da documentação e do registro no trabalho do(a) educador(a) infantil, Ostetto (2012) contrapõe os conceitos de chronos e kairós. Na Grécia Antiga, enquanto chronos era entendido como o tempo linear, isto é, o tempo do relógio, aquele que contamos, cronometramos etc., kairós conotava a ideia do tempo não-linear, o tempo em potencial ou "tempo-vida", como prefere Ostetto (2012). A autora sustenta que kairós é o tempo das crianças. Elas não estão preocupadas em contar o tempo, mas em vivê-lo, aproveitá-lo como oportunidade (outra acepção com a qual o termo kairós é encontrado). Entretanto, segundo Kohan (2004), kairós também remete a "medida" ou "proporção" - cabe citar aqui que, atualmente, na língua grega, a palavra kairós está associada ao tempo climático - e, em virtude disso, prefere associar a infância a um terceiro conceito grego de tempo: aión. O autor recorre a um fragmento de Heráclito (Wheelwright, 1959, p. 29, tradução nossa): "o tempo [aión] é uma criança movendo fichas num jogo; o régio poder é um poder de criança". ${ }^{3}$ Kohan (2004) leva em consideração uma dupla relação presente no fragmento: "tempo-infância" e "tempo-poder". Na visão do autor, a lógica temporal aiónica brinca com o afã de contabilizar o tempo e com essa contabilidade. A criança estabelece relação distinta com o tempo de modo que a infância não se limita a uma etapa da vida humana passível de ser mensurada, quantificada; trata-se, antes, de um reinado de potências intensivas, isto é, um tempo em que o movimento é expresso pela intensidade da duração e não pela sucessão de episódios ou oportunidades (kairós). De fato, se intensificamos a pesquisa pelas traduções de kairós e aión, é este último termo que comumente é traduzido por vida. Trata-se de um tempo que flerta (brinca) com a eternidade, que vivifica a vida, "aquele poder obscuro, impulsionador, inesgotável que deseja a si mesmo" (Nietzsche, 2003, p. 30) e que sempre quer vigorar.

A par das peculiaridades do tempo infantil, cabe ao educador cultivar sua capacidade sensível, sua atenção afetuosa para observar as crianças, que devem ser encaradas como portadoras do inédito (Fochi, 2015, p. 73), como usinas de intensidades, sujeitos ávidos por experienciar as potências de um tempo-vivo. Nessa atmosfera, elas encontram saídas que fogem aos lugares-comuns ou princípios universais. Apoiado em Malaguzzi ${ }^{4}$, Fochi (2015, p. 68) admite que "espantar-se com o mundo é algo fundamental para o crescimento da criança" e esse espanto requer sensibilidade. Somos
3 Utilizo aqui edição distinta da obra de Heráclito. Na edição de que se vale Kohan (2004), o fragmento supracitado consta como sendo o 52; na edição aqui usada, trata-se do fragmento 24 . Além disso, a tradução também é diferente. Enquanto Kohan (2004) utiliza a tradução de Alexandre Costa (Heráclito, 2000), optei pela tradução para o inglês do filósofo Philip Ellis Wheelwright (1959) e realizei a tradução para o português. Minha opção se deve ao fato da tradução de Wheelwright, no meu entendimento, contemplar melhor as categorias trabalhadas por Kohan (2004).

4 O educador italiano Loris Malaguzzi (1920-1994) foi o idealizador da abordagem pedagógica levada a cabo na localidade de Reggio Emilia. 
animais estéticos, nos subjetivamos por meio de nossas emoções e é necessário que educadoras e educadores infantis adotem uma postura que acolha esse espanto e saiba também se espantar.

Saber respeitar o tempo de cada criança, propiciar um ambiente favorável à sua exploração e acolher suas descobertas são, nesse sentido, tarefas essenciais. De fato, o registro pode contribuir e muito para a prática docente com crianças pequenas, mas, antes de tudo, é preciso ter tato para vivenciar os acontecimentos com os alunos e perceber as peculiaridades de suas descobertas que revelam traços de suas sensibilidades, seus desejos e de suas idiossincrasias. Em sentido lato, aliás, tato é uma das cinco faculdades por meio das quais somos capazes de perceber. Salvo exceções que etólogos e zoólogos estariam muito mais aptos para explicar, compartilhamos o sentido do tato com os demais animais. O significado atribuído por Helmholtz, evidentemente, transcende o sentido do termo no senso comum, mas preserva um imo de animalidade. O conceito de tato cunhado por Helmholtz (apud Gadamer, 1999, p. 57) traz à tona a sensibilidade como categoria fundamental para orientar a postura do sujeito que experiencia situações inusitadas e perante as quais não possui "nenhum saber baseado em princípios universais" capaz de guiar suas ações. De qualquer modo, certa sensibilidade para perceber o contexto situacional é um atributo animal, e o afeto pelos filhotes e a atenção cuidadosa a seus processos de exploração são qualidades comuns entre os mamíferos. As crias em idade tenra - e as humanas talvez em maior medida - criam alternativas inusitadas na medida em que exploram saídas para imbróglios para os quais os adultos geralmente já possuem soluções.

Em outras palavras, ao experimentarem diferentes possibilidades, as crianças produzem o inédito e, porque não dizer, "fazem arte" no duplo sentido da expressão. "Fazer arte" é bagunçar o mundo natural e produzir recursos de expressão inesperados (Cunha, 2012). Por meio da arte, o ser humano também supre uma tendência própria de sua animalidade: a transformação da natureza em cultura. Nesse sentido, as crianças, além de nos ensinarem a exercitar o tato e nos convidarem a tal exercício, evocam, a todo tempo, uma potência de nossa animalidade, ou seja, um caráter transformador.

Kafka, em seu conto Um Relatório para uma Academia, potencia essa discussão. O protagonista do conto narrado em primeira pessoa é um macaco. Ele se dirige a intelectuais revelando sua experiência de humanização. De acordo com o palestrante, os animais não se iludem com pretensões de liberdade, eles só querem uma saída, precisam de um horizonte que permita a continuidade de suas ações (Kafka, 1994). A exemplo dos bebês humanos, os animais se expressam e se revelam por meio de suas ações. Recordemos aqui o enunciado de Fochi (2015, p. 102) citado anteriormente: "a linguagem do bebê se vale de sua ação para se efetivar". Por isso eles são ávidos pela exploração, demonstram espanto em suas descobertas e encontram saídas inesperadas diante de situações em que nós adultos comumente recorremos a saberes-fazeres canônicos. 


\section{A organização do espaço e dos materiais}

Argumentei até este ponto que é importante estarmos atentos aos espaços das instituições de educação infantil e que a postura do(a) educador(a) deve permitir que a criança explore esses espaços sem, contudo, mencionar aspectos de como deve ser a sua organização. Este é o objetivo desta seção: elencar algumas características necessárias a espaços que propiciem a experiência do lúdico e assegurem o bem-estar das crianças. Antes, no entanto, cabe ressaltar que considero que as ponderações feitas por Nörnberg (2013) sobre o berçário são válidas também para as turmas de crianças maiores, de 2 a 5 anos de idade, e, nesta seção em particular, muitas características sugeridas para a organização dos espaços não necessariamente se aplicam à realidade do berçário.

Fortuna (2014) admite que arranjos espaciais semiabertos propiciam a formação de grupos. Eles "contam com a presença de zonas circunscritas sem que a visão fácil de todo o campo de ação seja prejudicada" (Fortuna, 2014 , p. 39). As crianças tendem a formar subgrupos dentro de uma mesma turma, ocupando essas zonas circunscritas. Essas experiências enriquecem a qualidade das relações e fomentam a sociabilidade dos pequenos. Os arranjos espaciais abertos, apesar de geralmente oferecerem mais espaço para a movimentação das crianças, tendem a centrar a atenção delas na figura do adulto e a reduzir a interação entre elas (Fortuna, 2014). Outro inconveniente dos arranjos espaciais abertos, dependendo da característica da turma, é o fato de ele poder servir de convite para que alguns alunos corram em sala de aula. Por se tratar de um espaço exíguo para esse tipo de brincadeira, as correrias podem gerar colisões e conflitos entre os educandos.

No que se refere aos materiais a serem disponibilizados às crianças e, em consonância com o que defende Fochi (2015), isto é, a mínima intervenção do(a) docente nas suas brincadeiras, Goldschmied e Jackson (2006, p. 52) escrevem o seguinte: "uma ampla gama de materiais cuidadosamente escolhidos e facilmente acessíveis estimula o brincar iniciado e dirigido pelas próprias crianças e permite ao adulto escolher o papel de facilitador, em vez de sempre dirigir as atividades". Decerto, a natureza dos materiais dependerá do perfil dos educandos e as intervenções do(a) educador(a) de seu tato para observá-los no decorrer de suas práticas. As autoras frisam, ainda, a importância de se ter na sala de aula o que elas chamam de "Cantinho Caseiro", que nada mais é do que um espaço preparado para a brincadeira de faz de conta com utensílios domésticos adaptados e apropriados para as crianças. Alguns itens, evidentemente, podem ser confeccionados pela própria turma com a ajuda de um adulto. Uma caixa de madeira virada pode, por exemplo, se transformar em um fogão. "Acima de tudo", recomendam Goldschmied e Jackson (2006, p. 47), "o 'Cantinho Caseiro' deve sempre parecer atraente e ordenado (mas não obsessivamente), para estimular o brincar individual e social". Fortuna (2014, p. 38) parece concordar que não deve haver obsessão pela ordem ao declarar que "salas muito arrumadas indicam que as crianças não agem, 
não brincam", mas destaca a necessidade de os alunos participarem da organização da sala e também de terem responsabilidade com ela.

Em relação aos materiais disponibilizados às crianças, uma alternativa interessante é apresentada no estudo de Horn, Silva e Pothin (2014). As autoras observaram a interação das crianças tanto na fabricação quanto na utilização de jogos feitos com sucata. "Nessa construção", declaram as autoras, "elas abandonam uma atitude passiva, de receber as coisas prontas e trabalhar mecanicamente, e passam a adotar uma postura ativa" (Horn; Silva; Pothin, 2014, p. 93). Entretanto, "quando se fala do trabalho com a sucata, em primeiro lugar, é preciso levar em consideração a seleção dos materiais" (Horn; Silva; Pothin, 2014, p. 93), por isso é preciso estar atento à apropriação dos materiais para cada faixa etária (levando em conta periculosidade, adequação às habilidades das crianças etc.) e a detalhes como a compatibilidade entre os próprios materiais e a proposta de confecção do brinquedo. Por exemplo, a disponibilização de objetos de difícil aderência que deverão ser colados pode fazer com que as crianças percam o interessem na atividade (Horn; Silva; Pothin, 2014). As autoras concluem:

Trabalhar com sucatas permite às crianças uma vivência pessoal, pois
temos que transformar, construir, criar, imaginar, interferindo nas
formas do objeto. O estilo pessoal de cada um de nós está presente
no objeto construído, uma vez que há espaço livre para a expressão,
a busca de novas formas, sem modelos e fórmulas preestabelecidas.
Também a manipulação com materiais de baixo custo disponibiliza
às crianças grandes possibilidades de brincar, não havendo formas
restritas de usar o material lúdico. (Horn; Silva; Pothin, 2014, p. 94).

Humanos, somos os animais que, indubitavelmente, mais interferimos no meio em que vivemos. O elã para transformar a natureza em cultura é visto por muitos pensadores como uma das principais características distintivas do humano em relação a outras espécies animais e é uma categoria largamente explorada na literatura educacional. Ora, é também modificando a natureza que nos humanizamos e aprendemos sobre ela e sobre nós mesmos. Atividades com sucata propiciam trabalhar esse pendor dos animais que somos desde muito cedo e, ademais, consistem em uma oportunidade para a livre expressão. Em contraposição aos materiais já estruturados (brinquedos prontos), que tendem a sugerir um modo específico de brincar, a sucata representa um recurso que instiga a imaginação das crianças e fomenta a criação de diferentes composições com a utilização de objetos bastante rudimentares. Além do uso da sucata para fabricar brinquedos, a simples disponibilização de materiais não estruturados tais como caixas, tampinhas, pedaços de madeira, latas etc., para que as crianças brinquem livremente, também é uma alternativa interessante para estimular a imaginação e trabalhar o impulso transformador próprio de nossa espécie.

Os ambientes, igualmente, influem em grande medida no desenvolvimento e no traquejo das potencialidades dos animais que somos. A organização dos espaços na educação infantil, nesse sentido, deve proporcionar certa qualidade à socialização das crianças (com arranjos 
espaciais semiabertos) e à acessibilidade aos brinquedos e materiais que são disponibilizados.

Seja na escolha dos materiais, seja na organização dos espaços, é sempre indispensável o olhar cuidadoso do profissional que trabalha com crianças. É importante ressaltar que o cuidado não se resume à atenção dedicada aos corpos das crianças e suas interações. Segundo o argumento aqui defendido, cuidar é uma disposição formativa inerente à nossa animalidade, que está a serviço do desenvolvimento de "seres-nomundo-juntos-das-coisas-com-outros" (Nörnberg, 2013) e que precisa estar presente nas práticas pedagógicas - independente do público com que são levadas a cabo -, mas, sobremaneira, nas que envolvem crianças pequenas.

\section{Desenvolvendo os animais que somos}

O subtítulo deste artigo, para muitos, pode trazer um paradoxo. O desenvolvimento humano, do ponto de vista civilizacional, geralmente é entendido como um processo por meio do qual nossa espécie se afastou da animalidade. Comumente nos esforçamos para qualificar o ser humano com adjetivos que o distinguem dos demais animais. No entanto, a despeito de nosso indiscutível potencial de transformar drasticamente a natureza, que nos dá certa supremacia em relação às demais espécies, obviamente não deixamos e jamais deixaremos de ser animais.

Frequentemente nos deparamos com a afirmação de que somos os animais que dedicamos mais cuidados aos nossos filhotes. Tal afirmação é perigosa por, pelo menos, três motivos: (1) por demandar uma demarcação precisa do conceito de cuidado que geralmente não é feita; (2) pelo fato de os que a afirmam, salvo raras exceções, não avaliarem os cuidados que outras espécies dedicam a seus filhotes; e (3) porque ainda que essas duas primeiras tarefas fossem cumpridas, tratar-se-ia de uma variável comportamental cuja mensuração seria, para dizer o mínimo, bastante problemática.

O que podemos afirmar, entretanto, é que nossas crias nascem vulneráveis e com os sentidos pouco apurados, de sorte que, se não fossem acompanhadas e cuidadas por indivíduos adultos durante boa parte de suas vidas, dificilmente seriam capazes de sobreviver. Somos animais que, mais do que cuidar, buscamos educar intencionalmente nossos filhotes desde idade bastante precoce; pouco pensamos sobre os impulsos que os animais que somos manifestam desde muito cedo em nossa autoconstrução, isto é, no protagonismo de nossa própria formação. Deveríamos refletir mais sobre a infância para aprender com as crianças sobre nossa animalidade. Sua avidez para explorar o mundo, suas ações e a manifestação de suas emoções em suas descobertas são experiências que precisam ser vividas para o desenvolvimento da personalidade e da cognição, mas também dos atributos animais de nossa espécie. É preciso deixar que o corpo e os gestos falem; dar liberdade para que o animal brincante se emocione, imagine e fantasie ao brincar; tornar o espaço um ambiente acolhedor e seguro para que o "tempo-vida" possa ser vivido; ter tato e acolher a diversidade 
de linguagens e modos de ser das crianças; permitir que interajam como crianças e usem seus sentidos para se descobrirem; e, como mamíferos que somos, propiciar aos pequenos uma pedagogia de afeto e cuidado.

Nada disso tem a ver apenas com humanidade. As crianças são uma usina de potências da animalidade humana. Por sorte, vivemos um momento histórico em que a pedagogia da primeira infância começa a ganhar alguma atenção, e creio que a observação das crianças e a reflexão sobre métodos, instrumentos, espaços e intervenções adequadas ao cuidado e à educação na educação infantil nos levará, mais cedo ou mais tarde, a problematizar os valores e a eficácia de determinadas práticas para os animais que somos e que queremos que nossos filhotes se tornem. Em suma, condutores de crianças que somos, nós pedagogos ${ }^{5}$ devemos também nos deixar conduzir pelas potencialidades de que as crianças estão prenhes. Isso requer uma postura cuidadosa e sensível, requer um tato para que se saiba lidar com tempos, espaços e intensidades que são importantes variáveis na formação de crianças pequenas. Esse tato passa pela disposição para cuidar que é própria de nossa espécie.

\section{Referências}

BARBOSA, M. C. S.; HORN, M. G. S. Projetos pedagógicos na educação infantil. Porto Alegre: Artmed, 2008.

BRASIL. Conselho Nacional de Educação (CNE). Câmara de Educação Básica (CEB). Resolução no 5, de 17 de dezembro de 2009. Fixa as Diretrizes Curriculares Nacionais para a Educação Infantil. Diário Oficial da União, Brasília, DF, 18 dez. 2009. Seção 1, p. 18.

CAMPOS, M. M. et al. A qualidade da educação infantil: um estudo em seis capitais brasileiras. Cadernos de Pesquisa, São Paulo, v. 41, n. 142, p. 20-54, 2011.

CUNHA, S. R. V. A importância das artes na infância. In: CUNHA, S. R. V. (Org.). As artes no universo infantil. Porto Alegre: Mediação, 2012. p. 13-56.

DEBORTOLI, J. A. et al. Projeto Brincar: experiências e memórias de brincadeiras na educação básica e na formação de professores. In: CARVALHO, A. et al. (Orgs.). Brincar(es). Belo Horizonte: Ed. da UFMG, 2009.

FARIA, V.; SALLES, F. Currículo na educação infantil. São Paulo: Scipione, 2007.

FOCHI, P. Afinal, o que os bebês fazem no berçário? Porto Alegre: Penso, 2015.

FORTUNA, T. R. A importância de brincar na infância. In: HORN, C. I. et al. Pedagogia do brincar. Porto Alegre: Mediação, 2014. 
GADAMER, H. G. Verdade e método: traços fundamentais de uma hermenêutica filosófica. Petrópolis: Vozes, 1999.

GOLDSCHMIED, E.; JACKSON, S. Educação de 0 a 3 anos: o atendimento em creches. Porto Alegre: Artmed, 2006.

HEIDEGGER, M. Sobre o humanismo. Rio de Janeiro: Tempo Brasileiro, 1967.

HERÁCLITO. Fragmentos. Tradução de Alexandre Costa. Rio de Janeiro: Difel, 2000.

HORN, C. I.; SILVA, J. S.; POTHIN, J. Jogar e brincar com materiais de baixo custo. In: HORN, C. I. et al. Pedagogia do brincar. Porto Alegre: Mediação, 2014.

KAFKA, F. Um médico rural: pequenas narrativas. São Paulo: Brasiliense, 1994.

KOHAN, W. O. A infância da educação: o conceito devir-criança.

In: KOHAN, W. O. (Org.). Lugares da infância: filosofia. Rio de Janeiro: DP\&A, 2004.

LIBÂNEO, J. C. Democratização da Escola Pública: a pedagogia críticosocial dos conteúdos. São Paulo: Loyola, 2001.

NIETZSCHE, F. W. Segunda consideração intempestiva, da utilidade e desvantagem da história para a vida. Rio de Janeiro: Relume Dumará, 2003.

NÖRNBERG, M. Do berço ao berçário: a instituição como morada e lugar de contato. Pro-posições, Campinas, v. 24, n. 3, p. 99-113, set./dez. 2013.

OSTETTO, L. E. Observação, registro, documentação: nomear e significar as experiências. In: OSTETTO, L. E. (Org.). Educação infantil: saberes e fazeres da formação de professores. Campinas: Papirus, 2012.

PEREIRA, E. T. Brincar e criança. In: CARVALHO, A. et al. (Orgs.).

Brincar(es). Belo Horizonte: Ed. da UFMG, 2009.

SANTOS, V. L. B. Da brincadeira de faz de conta à representação teatral. In: CUNHA, S. R. V. (Org.). As artes no universo infantil. Porto Alegre: Mediação, 2012.

WHEELWRIGHT, P. Universal flux. In: WHEELWRIGHT, P. Heraclitus. Princetown: Princetown University Press, 1959.

Recebido em 11 de junho de 2018.

Aprovado em 27 de novembro de 2018. 